\title{
ABSTRACT \\ EFFECT OF DIGITAL HIGHLIGHTING ON READING COMPREHENSION GIVEN TEXT-TO-SPEECH TECHNOLOGY FOR PEOPLE WITH APHASIA
}

by Camille Rae deVille

Many people with aphasia have a desire to participate in reading activities despite persistent reading challenges. Digital reading devices and text-to-speech (TTS) technology are increasing in popularity and have the potential to help people with aphasia. Systematic investigation of modifiable TTS features provides a means of exploring this potential. This study's primary aim was to evaluate the effect of digital highlighting synchronized with TTS on reading comprehension by people with aphasia. A secondary purpose was to explore the highlighting preferences of people with aphasia. Twenty-five adults with aphasia read and listened to passages presented in three synchronized highlighting conditions: sentence highlighting, single word highlighting, and no highlighting. Participants answered comprehension questions, selected most and least preferred conditions, and provided feedback explaining highlighting preferences. Comprehension accuracy did not vary significantly across presentation conditions, but participants preferred either single word or sentence highlighting over no highlighting. Neither word or sentence highlighting benefitted nor hindered comprehension by people with aphasia as a group, but individual differences were evident. Clinicians should attend to individual preferences when implementing digital highlighting as a reading support strategy. 


\title{
EFFECT OF DIGITAL HIGHLIGHTING ON READING COMPREHENSION GIVEN
} TEXT-TO-SPEECH TECHNOLOGY FOR PEOPLE WITH APHASIA

\author{
Thesis \\ Submitted to the \\ Faculty of Miami University \\ in partial fulfillment of \\ the requirements for the degree of \\ Master of Arts \\ by \\ Camille Rae deVille \\ Miami University \\ Oxford, Ohio \\ 2020 \\ Advisor: Kelly Knollman-Porter, Ph.D., CCC-SLP \\ Reader: Jessica Brown, Ph.D., CCC-SLP \\ Reader: Arnold Olszewski, Ph.D., CCC-SLP \\ Reader: Courtney Robinson, M.S., CCC-SLP
}

C2020 Camille Rae deVille 
This thesis titled

\section{EFFECT OF DIGITAL HIGHLIGHTING ON READING COMPREHENSION GIVEN TEXT-TO-SPEECH TECHNOLOGY FOR PEOPLE WITH APHASIA}

by

Camille Rae deVille

has been approved for publication by

The College of Arts and Science

and

Department of Speech Pathology and Audiology

Kelly Knollman-Porter

Jessica Brown

Arnold Olszewski

Courtney Robinson 


\section{Table of Contents}

Introduction.............................................................................. 1

Cognitive and Linguistic Contributions to Reading................................ 1

Benefits of Text Highlighting................................................. 2

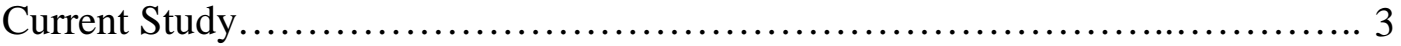

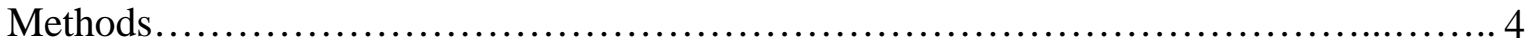

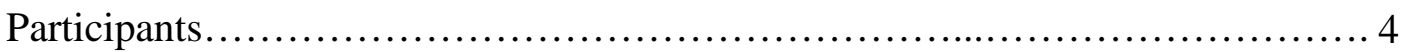

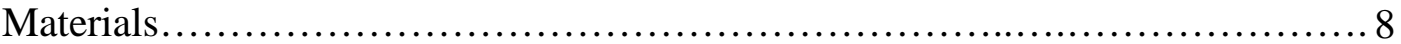

Newspaper Articles.................................................. 8

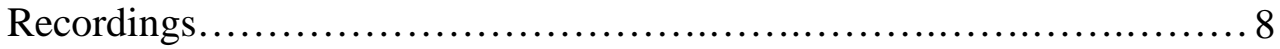

Comprehension Questions.......................................... 9

Stimulus Presentation.................................................... 9

Preference Selection Materials.......................................... 10

Procedures................................................................... 10

Stimulus Articles and Comprehension Question Presentations................. 10

Participant Preference................................................. 11

Data Analysis................................................................ 11

Comprehension Accuracy........................................... 11

Participant Condition Preference......................................... 11

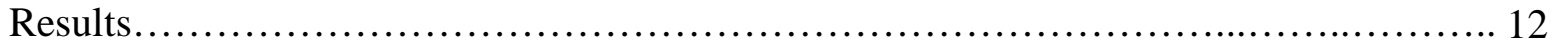

Comprehension Accuracy ................................................... 12

Unique Individual Cases...................................................... 13

Condition Preferences and Perceptions........................................... 13

Participant Explanations for Highlighting Preferences............................. 14

Sentence Highlighting............................................... 14

Single Word Highlighting.......................................... 16

No Highlighting................................................... 18

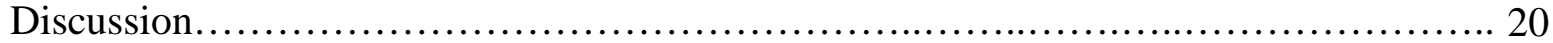

Comprehension Accuracy .................................................... 20

Individual Differences....................................................... 21

Highlighting Preference.................................................. 22

Clinical Application......................................................... 22

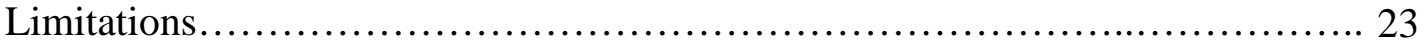

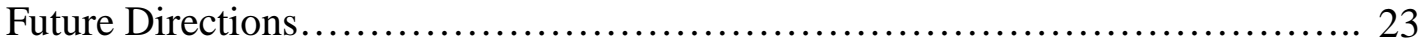

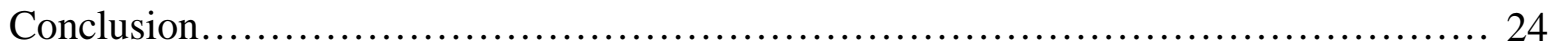

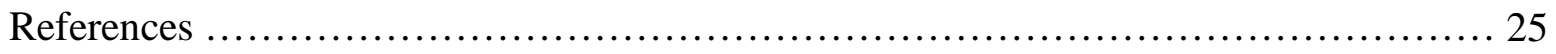

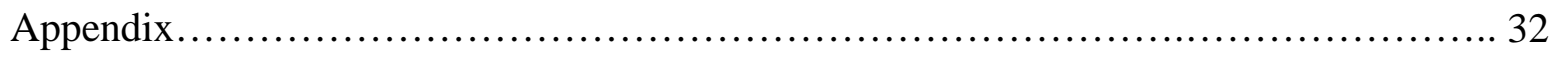




\section{List of Tables}

Table 1. Participant Demographic Information..................................... 5

Table 2. Participant Standardized Test Scores.......................................... 7

Table 3. Participant Accuracy Across Fluency Groups..................................12

Table 4. Number of Participants Preferring each Highlighting Condition...................14 


\section{List of Figures}

Figure 1. Participants’ Percent Accuracy Across Conditions........................... 12

Figure 2. Participant Opinions about Sentence Highlighting......................... 16

Figure 3. Participant Opinions about Single Word Highlighting. ....................... 18

Figure 4. Participant Opinions about No Highlighting .............................. 20 


\section{Dedication}

To my sister, Grace... for the continued support and love. If I can do it, so can you. 


\section{Acknowledgments}

This work was supported by the National Institute on Deafness and other Communication Disorders of the National Institutes of Health under award number 1R15DC015579. The content is solely the responsibility of the authors and does not necessarily represent the view of the National Institutes of Health.

First, and most of all, I would like to thank Dr. Kelly Knollman-Porter, for her expertise, assistance, guidance, and patience throughout the process of writing this thesis. Without your help and support this paper would not have been possible. I would like to thank my committee members, Dr. Jessica Brown, Dr. Arnold Olszewski, and Ms. Courtney Robinson, for their dedication to the field and commitment to their students. Thank you to Dr. Karen Hux and Dr. Sarah Wallace for many generous and helpful suggestions.

I would like to extend my sincere gratitude to the exceptional faculty in the Speech Pathology and Audiology Department at Miami University. Your continual support and encouragement are much appreciated.

Finally, I would like to thank everyone helped contribute to this project; and to my best friends, Molly, Margaret, Elizabeth, Jaqueline and Colleen, thanks for always being there for me and for helping me get through this program. 


\section{Effect of Digital Highlighting on Reading Comprehension Given Text-to-Speech}

Technology for People with Aphasia

Digital reading devices and text-to-speech (TTS) technology are readily available and increasingly popular among people of all ages. For some adults with aphasia, using TTS technology facilitates comprehension of written material by presenting written and auditory content simultaneously (Knollman-Porter et al., 2019; Wallace et al., 2019). An important aspect of this benefit is that TTS systems have presentation features (e.g., voice, rate, highlighting) that are modifiable to match individual comprehension needs and preferences.

Rehabilitation specialists can modify traditional reading materials to meet aphasiafriendly formatting standards by providing abundant white space, using large and standard fonts, and simplifying sentence structures and vocabulary (Brennan et al., 2005). Although helpful, making these modifications can be time-consuming for clinicians or caregivers, may not match the unique reading preferences of a person with aphasia, and may not provide adequate benefit to allow independent participation in daily reading activities. Advances in TTS technology provide an alternative method of individualizing written content presentation. One TTS feature-that is, digital highlighting of single words or sentences—-is the focus of the current research.

Highlighting words or sentences as they are spoken may improve attention to the text, thereby facilitating comprehension; however, researchers have yet to systematically evaluate this possibility with respect to people with aphasia.

\section{Cognitive and Linguistic Contributions to Reading}

Reading is a complex task requiring the coordination of multiple bottom-up and topdown cognitive and linguistic processes (Cutting et al., 2009; Hook \& Crawford-Brooke, 2015; Rashotte et al., 2001). Bottom-up processing involves identifying printed words through decoding or whole word recognition (Hook \& Crawford-Brooke, 2015; Rashotte et al., 2001). In contrast, top-down processing promotes comprehension through constructing and extracting meaning from contextual and structural cues in the text (Cutting et al., 2009; Hook \& CrawfordBrooke, 2015). Skilled readers are efficient in coordinating bottom-up and top-down processes to decode and comprehend text (Gibson, 2006; Johnson \& Rayner, 2007; Rayner \& Johnson, 2005; Samuels \& Flor, 1997). They do this by retrieving and categorizing word meanings into grammatical units while engaging higher cognitive processes to understand text structure and self-monitor comprehension (Kendeou et al., 2014; Oakhill \& Cain, 2012; Oakhill \& Yuill, 
2013; Perfetti et al., 2013). The result is creation of a cohesive and logical mental model of a text that is revised and refined as new information is presented (Jiang \& Farquharson, 2018).

Cognitive processes such as attention, memory, and executive function are essential for successful processing of written content (Catts et al., 1999; Sesma et al., 2009; Swanson, 1999). As such, researchers have documented a relation between poor attention and poor reading comprehension (Brock \& Knapp, 1996; Martinussen \& Mackenzie, 2015). This relation appears to reflect the negative effects of impaired allocation of cognitive resources on the integration of ideas and construction of mental models (Kendeou et al., 2014). Similarly, researchers have found that intact working memory is critical for coordinating and manipulating the construction of mental models while reading (Cain et al., 2004). Hence, people with good working memory tend to have better reading comprehension than people with poor working memory (Cain et al., 2004; Carretti et al., 2009; Seigneuric \& Ehrlich, 2005; Seigneuric et al., 2000).

People with aphasia often have both attention and working memory deficits that may affect decoding and reading comprehension efforts (Friedmann \& Gvion, 2003; Wright \& Shisler, 2005). In accordance with resource allocation theory, the language processing and production challenges of people with aphasia reflect insufficient attention capacity and/or inefficient allocation of attentional resources (Hula \& McNeil, 2008; McNeil et al., 1991; Murray, 1999). Some people with aphasia have attention problems that make inhibiting irrelevant stimuli difficult when reading (Martin \& Allen, 2008). These attention problems affect reading comprehension by decreasing creation of a mental model and integration of ideas. Similarly, working memory deficits of people with aphasia may impede the updating and coordination of incoming information (Baddeley, 2000; Ericsson \& Kintsch, 1995), again negatively affecting text comprehension. Because attention is fundamental to memory (Baddeley et al., 1995; Huppert \& Piercy, 1982; Posner \& Petersen, 1990), impaired utilization of working memory when reading may stem from poor attention to the written text.

\section{Benefits of Text Highlighting}

People with aphasia frequently exhibit reading difficulty characterized by trouble with both decoding words and comprehending written materials (Knollman-Porter et al., 2015; Leff \& Behrmann, 2008). Some may experience difficulty with decoding at the single word level, while others exhibit difficulty with more complex comprehension tasks (Knollman-Porter et al., 2015). Synchronizing digital text highlighting with auditory TTS output may benefit people with 
aphasia by improving attention to salient text elements during the reading process. In turn, increased attention may promote improved working memory to process and construct a mental model of presented material.

The intuitive appeal of this rationale has prompted research about using digitally highlighted TTS with children with developmental reading problems; however, findings from such studies have not always borne out expected benefits. For example, Ayres, Langone, Douglas, Mead, and Bell (2008) studied the effects of highlighted TTS output on comprehension by students with moderate intellectual disabilities. Findings indicated that, for the group as a whole, digital highlighting did not improve reading comprehension significantly; however, some individual participants experienced improved comprehension. More recent research by Keelor (2017) confirmed the finding of no significant comprehension benefit for a group of students with reading difficulties when processing passages with digitally highlighted TTS output. However, to explore this finding further, Keelor, Creaghead, Silbert, Breit-Smith, and HorowitzKraus (2018) investigated the relation among measures of reading comprehension and measures of language and executive function. Results revealed a significant positive relation between language skills and reading comprehension given TTS presentation either with or without digital highlighting; no comprehension accuracy difference occurred between highlighted and nonhighlighted TTS presentations. Thus, students with reading problems who benefitted most from TTS output were those for whom language functioning was a relative strength; the addition of digital highlighting did not further increase the benefit gained from TTS. Whether people with aphasia will experience the same or disparate outcomes when provided TTS output with synchronized highlighting remains to be determined.

\section{Current Study}

Researchers have documented comprehension benefits for some adults with aphasia given simultaneous written and auditory presentation (Knollman-Porter et al., 2019; Wallace et al., 2019). People with aphasia benefit from aphasia-friendly formatting that uses large font sizes and has abundant white space (Brennan et al., 2005). Given these findings, investigating whether the addition of synchronous highlighting to TTS output as a visuographic text manipulation is of interest. Such manipulation may enhance attention to written words and increase comprehension beyond that evidenced with multimodal text presentation alone or with other visuographic modifications suggested as aspects of aphasia-friendly formatting. Additionally, people with 
aphasia may experience varying degrees of benefit when text highlighting occurs at word versus sentence levels. Therefore, the primary purpose of the current study was to examine the comprehension accuracy of adults with chronic aphasia when presented with written and spoken TTS output of newspaper articles that varied in accordance with three synchronized highlighting conditions: no highlighting, single word highlighting, and sentence highlighting. A secondary purpose was to explore the highlighting preferences of people with aphasia. Research questions included:

- How does comprehension accuracy by people with aphasia vary when processing (1) written content presented with TTS output and no highlighting, (2) synchronized single word highlighting, or (3) synchronized sentence highlighting?

- What are the highlighting preferences of people with aphasia when processing written content presented with TTS output?

\section{Methods}

\section{Participants}

Study participants included 14 males and 11 females with chronic aphasia. They ranged in age from 35 to 78 years $(M=59.20, S D=11.15)$, were between ten and 266 months poststroke or stable encephalopathy $(M=116.68, S D=72.90)$, and had completed between 12 and 19 years of education $(M=14.76, S D=2.30)$. All participants were right hand dominant prior to acquiring aphasia and spoke American English as their primary language. Participants passed a hearing screening confirming perception of $1000 \mathrm{~Hz}, 2000 \mathrm{~Hz}$, and $4000 \mathrm{~Hz}$ tones presented at $40 \mathrm{~dB}$ in at least one ear. Two participants (i.e., Q and W) regularly wore hearing aids and, thus, did not complete hearing screenings; both had received audiology services within the past year and demonstrated adequate hearing of conversational speech with aids in place. All participants passed a visual acuity screening requiring accurate identification of their first name in each of ten sets of five names; all names appeared in black, 24-point, Times New Roman font on a laptop computer. Participant demographic information appears in Table 1. 


\begin{tabular}{|c|c|c|c|c|c|c|c|c|}
\hline Participant & Race & Gender & $\begin{array}{c}\text { Age } \\
\text { (years) }\end{array}$ & $\begin{array}{c}\text { Education } \\
\text { level (years) }\end{array}$ & $\begin{array}{c}\text { Time post- } \\
\text { onset (months) }\end{array}$ & $\begin{array}{c}\text { Currently } \\
\text { receiving } \\
\text { SLP }^{1} \text { services }\end{array}$ & $\begin{array}{c}\text { Employment } \\
\text { status }\end{array}$ & Living status \\
\hline $\mathrm{A}$ & White & Male & 52 & 12 & 158 & No & Retired & Independent \\
\hline B & White & Female & 74 & 16 & 240 & No & Retired & Spouse \\
\hline $\mathrm{C}$ & White & Female & 64 & 12 & 241 & No & Retired & Spouse \\
\hline $\mathrm{D}$ & White & Female & 73 & 12 & 88 & No & Retired & Spouse \\
\hline $\mathrm{E}$ & White & Female & 35 & 18 & 51 & No & Disability & Spouse \\
\hline $\mathrm{F}$ & White & Male & 50 & 16 & 135 & No & Disability & Spouse \\
\hline G & White & Female & 52 & 16 & 131 & No & Disability & Children \\
\hline $\mathrm{H}$ & Black & Male & 57 & 14 & 91 & No & Disability & Parent \\
\hline I & White & Female & 60 & 12 & 83 & No & Retired & Spouse \\
\hline $\mathrm{J}$ & White & Male & 47 & 12 & 118 & No & Part-time & Parent \\
\hline $\mathrm{K}$ & Black & Female & 52 & 16 & 75 & No & Disability & $\mathrm{ECF}^{2}$ \\
\hline $\mathrm{L}$ & White & Female & 73 & 12 & 132 & No & Retired & Partner \\
\hline $\mathrm{M}$ & White & Male & 71 & 18 & 266 & No & Retired & Independent \\
\hline $\mathrm{N}$ & White & Male & 57 & 16 & 108 & Yes & Retired & Spouse \\
\hline $\mathrm{O}$ & White & Female & 58 & 18 & 23 & Yes & Volunteer & Independent \\
\hline $\mathrm{P}$ & White & Female & 49 & 16 & 93 & Yes & Retired & Parent \\
\hline $\mathrm{Q}$ & White & Male & 78 & 18 & 68 & Yes & Retired & Spouse \\
\hline $\mathrm{R}$ & White & Male & 73 & 15 & 38 & No & Retired & Spouse \\
\hline $\mathrm{S}$ & White & Male & 65 & 16 & 23 & Yes & Retired & Spouse \\
\hline $\mathrm{T}$ & White & Male & 47 & 16 & 185 & Yes & Part-time & Independent \\
\hline $\mathrm{U}$ & White & Female & 44 & 12 & 25 & No & Retired & Parent \\
\hline $\mathrm{V}$ & White & Male & 55 & 12 & 156 & Yes & Volunteer & Family \\
\hline W & Black & Male & 71 & 16 & 196 & No & Retired & Spouse \\
\hline$X$ & White & Male & 60 & 12 & 183 & Yes & Part-time & Independent \\
\hline $\mathrm{Y}$ & White & Male & 63 & 16 & 10 & Yes & Retired & Spouse \\
\hline
\end{tabular}

${ }^{1} \mathrm{SLP}=$ speech-language pathology

${ }^{2} \mathrm{ECF}=$ extended care facility. 
We assessed participants' language and cognitive abilities through standardized batteries and subtests administered prior to study initiation. Language assessments included the Aphasia Quotient portion of the Western Aphasia Battery - Revised (WAB-R; Kertesz, 2006); the Comprehension of Spoken Sentences, Spoken Paragraphs, and Written Sentences subtests of the Comprehensive Aphasia Test (CAT; Swinburn et al., 2004); and the Paragraph Factual subtest of the Reading Comprehension Battery for Aphasia $-2^{\text {nd }}$ Edition (RCBA-2; LaPointe \& Horner, 1998). To gather information about cognitive skills, we administered the Cognitive Linguistic Quick Test + (CLQT+; Helm-Estabrooks, 2017). Testing results for each participant appear in Table 2.

WAB-R Aphasia Quotient scores ranged from 15.60 to $97.20(M=59.49, S D=20.86)$. In accordance with cut-off scores provided in the $W A B-R$ manual, two participants exhibited very severe aphasia (i.e., scores $\leq 25$ ), six exhibited severe aphasia (i.e., scores between 26 and 50), 12 exhibited moderate aphasia (i.e., scores between 51 and 75), and four exhibited mild aphasia (i.e., scores between 76 and 93.8; Kertesz, 2006). The remaining participant (i.e., W) achieved an aphasia quotient above the cut-off for an aphasia diagnosis per WAB-R standards but had a clinical diagnosis of aphasia and displayed language challenges on other administered measures (see Table 2). Twelve participants displayed characteristics of fluent aphasia, and 13 participants displayed characteristics of non-fluent aphasia. 
Table 2

Participant Standardized Test Scores

\begin{tabular}{|c|c|c|c|c|c|c|c|c|c|c|c|c|}
\hline \multirow[b]{2}{*}{ Participant } & \multirow[b]{2}{*}{ Aphasia type } & \multirow[b]{2}{*}{$\begin{array}{l}\text { Fluency } \\
\text { type }\end{array}$} & \multirow{2}{*}{ 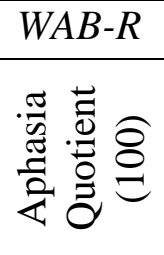 } & \multicolumn{5}{|c|}{$C L Q T+$ Domains } & \multicolumn{3}{|c|}{ CAT Subtests } & \multirow{2}{*}{ 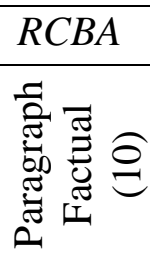 } \\
\hline & & & & 总怘 & 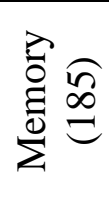 & 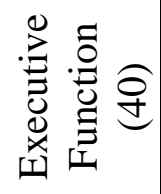 & 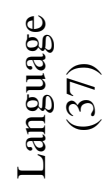 & 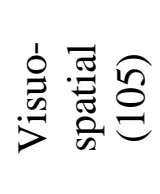 & 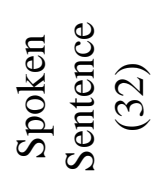 & 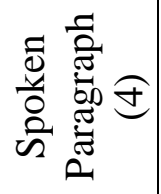 & 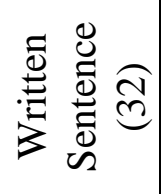 & \\
\hline A & Anomic & Fluent & 66.6 & 165 & 142 & 22 & 22 & 88 & 16 & 1 & 13 & 7 \\
\hline B & Broca's & Nonfluent & 27.0 & 136 & 66 & 8 & 1 & 66 & 21 & 2 & 22 & 9 \\
\hline $\mathrm{C}$ & Conduction & Fluent & 72.3 & 197 & 144 & 25 & 26 & 93 & 25 & 4 & 20 & 9 \\
\hline $\mathrm{D}$ & Transcortical Sensory & Fluent & 67.1 & 156 & 106 & 13 & 12 & 72 & 22 & 3 & 24 & 7 \\
\hline $\mathrm{E}$ & Anomic & Fluent & 92.2 & 203 & 160 & 27 & 27 & 99 & 23 & 4 & 22 & 10 \\
\hline $\mathrm{F}$ & Conduction & Fluent & 69.6 & 200 & 144 & 32 & 26 & 102 & 28 & 4 & 26 & 9 \\
\hline $\mathrm{G}$ & Broca's & Nonfluent & 47.9 & 182 & 108 & 24 & 12 & 95 & 20 & 1 & 22 & 9 \\
\hline $\mathrm{H}$ & Broca's & Nonfluent & 67.8 & 192 & 146 & 24 & 23 & 94 & 25 & 3 & 28 & 10 \\
\hline $\mathrm{I}$ & Broca's & Nonfluent & 64.6 & 176 & 162 & 22 & 27 & 86 & 16 & 4 & 24 & 10 \\
\hline $\mathrm{J}$ & Wernicke's & Fluent & 64.2 & 188 & 126 & 25 & 23 & 91 & 19 & 2 & 20 & 7 \\
\hline $\mathrm{K}$ & Wernicke's & Fluent & 49.2 & 124 & 109 & 9 & 25 & 53 & 16 & 2 & 16 & 7 \\
\hline $\mathrm{L}$ & Broca's & Nonfluent & 55.5 & 125 & 92 & 18 & 17 & 68 & 19 & 4 & 20 & 9 \\
\hline M & Anomic & Fluent & 81.3 & 176 & 145 & 19 & 27 & 29 & 26 & 4 & 26 & 9 \\
\hline $\mathrm{N}$ & Broca's & Nonfluent & 34.9 & 164 & 77 & 16 & 7 & 76 & 16 & 2 & 12 & 3 \\
\hline $\mathrm{O}$ & Broca's & Nonfluent & 86.2 & 134 & 136 & 17 & 28 & 52 & 19 & 4 & 17 & 10 \\
\hline $\mathrm{P}$ & Broca's & Nonfluent & 48.3 & 184 & 88 & 19 & 11 & 92 & 16 & 2 & 14 & 9 \\
\hline $\mathrm{Q}$ & Conduction & Fluent & 60.7 & 124 & 57 & 13 & 13.5 & 51 & 15 & 2 & 15 & 5 \\
\hline $\mathrm{R}$ & Broca's & Nonfluent & 52.6 & 73 & 53 & 20 & 7 & 60 & 28 & 4 & 24 & 9 \\
\hline $\mathrm{S}$ & Global & Nonfluent & 19.6 & 81 & 50 & 21 & 0 & 63 & 2 & 0 & 3 & 4 \\
\hline $\mathrm{T}$ & Broca's & Nonfluent & 59.7 & 147 & 82 & 17 & 16 & 67 & 16 & 3 & 10 & 4 \\
\hline $\mathrm{U}$ & Broca's & Nonfluent & 15.6 & 172 & 72 & 17 & 2 & 83 & 23 & 4 & 19 & 9 \\
\hline $\mathrm{V}$ & Conduction & Fluent & 45.0 & 155 & 90 & 22 & 16 & 67 & 10 & 3 & 9 & 7 \\
\hline $\mathrm{W}$ & Anomic & Fluent & 97.2 & 176 & 127 & 21 & 23 & 83 & 26 & 3 & 18 & 4 \\
\hline $\mathrm{X}$ & Broca's & Nonfluent & 61.5 & 192 & 91 & 26 & 15 & 94 & 15 & 2 & 13 & 8 \\
\hline $\mathrm{Y}$ & Conduction & Fluent & 80.6 & 201 & 158 & 31 & 29.5 & 99 & 18 & 3 & 24 & 10 \\
\hline
\end{tabular}




\section{Materials}

Study materials included written and auditory presentations of edited articles from newspapers, researcher-generated comprehension questions about each article, Kurzweil $3000^{\circledR}$ software and ApowerREC ${ }^{\circledR}$ screen recording software for stimulus development, laptop computers with E-Prime ${ }^{\circledR} 3.0$ software for stimulus presentation, and a Canon HF R700 or R800 digital video camera to record participant comments.

Newspaper articles. Experimental stimuli included 39 edited newspaper articles (i.e., 36 experimental articles and three practice articles). All stimulus articles came from US newspapers available online and met the following criteria: (a) did not report news local to the region in which participants lived, (b) did not report national news, (c) did not report general knowledge information (e.g., World Series results), and (d) only used acronyms assumed to be comprehensible without explanation to all participants (e.g., United States = US).

We edited the newspaper articles to be of consistent length and readability for research purposes (Knollman-Porter et al., 2019; Hux et al., in press). Furthermore, we sought to create stimuli consistent with materials people with aphasia were likely to encounter in real-world settings while maintaining reading levels and lengths mostly comprehensible by people with language challenges. To determine an appropriate grade-level for experimental articles, we evaluated the Flesch-Kincaid grade-level (Flesch, 1948) of 69 randomly selected, unedited newspaper articles. These articles had grade-level equivalencies ranging from 6.5 to 13.0 ( $M=$ 9.93, $S D=1.69$ ). Based on this information, we stipulated a grade equivalency between 9.0 and 11.0 for each stimulus article $(M=9.99, S D=.57)$. In addition, we edited stimulus articles to make each between 180 and 220 words in length $(M=202.28, S D=12.56)$ which was consistent with short articles found in online newspapers. Editing articles to meet the length and grade level criteria involved removing complete sentences only; we made no single word or phrase substitutions or deletions and did not rearrange any sentences. Each edited article contained no more than two quotes. Finalized edited articles ranged from eight to 15 sentences in length $(M=$ 10.72, $S D=1.86)$.

Recordings. We used the Kurzweil $3000^{\circledR}$ software to create digital video screen displays of experimental and practice articles. Kurzweil $3000^{\circledR}$ is adaptive educational software designed to provide support to people with reading challenges. We chose this software because it allows a user to customize the type (i.e., single word, sentence, or paragraph) and color of highlighting. 
Each article appeared on the system with 24-point, Times New Roman font centered on a white background; highlighting appeared as a yellow bar surrounding the desired text during highlighting conditions. Within the Kurzweil $3000^{\circledR}$ settings, we set each article to be read by the computer-generated David voice from the Windows platform at a speed of 145 words per minute. We chose the David voice because people with aphasia can comprehend it at this speaking rate and prefer it to some other computer-generated voices (Hux et al., 2017). We chose the speaking rate of 145 words per minute because, as a group, people with aphasia prefer this rate to one that is substantially faster or slower (Hux et al., in press). Of note, when creating stimuli for the sentence-length highlighting condition, the Kurzweil $3000^{\circledR}$ highlighting function sometimes extended beyond a single sentence or stopped mid-sentence. To maintain consistency across stimuli and ensure highlighting of each sentence in its entirety, we added white periods between sentences on nine occasions and removed periods in abbreviations on eight occasions.

We captured and saved as separate files three audio and video recordings of each article using ApowerREC ${ }^{\circledR}$ software. The three recordings per article corresponded with three experimental conditions: no highlighting, synchronized single word highlighting, and synchronized sentence highlighting.

Comprehension questions. We generated six comprehension questions for each article. All questions appeared as incomplete sentences with the final word or phrase deleted. Each question was factual in nature and used verbiage consistent with that of the article. We presented each question in multiple choice format in which a vertical list appearing after the sentence stem contained the target response and three foil responses. Target responses occurred in each of the four answer positions approximately the same number of times. We completed a dependency analysis following procedures used in previously published work (Hux et al., in press) to ensure that, as a group, adults without reading challenges responded with less than $40 \%$ accuracy to each comprehension question given an established question presentation order and without prior reading of the corresponding article.

Stimulus presentation. We used 17-inch Dell touchscreen laptop computers to present experimental stimuli using E-Prime ${ }^{\circledR}$ software. Use of E-Prime ${ }^{\circledR} 3.0$ allowed for controlled and systematic stimulus presentation along with data logging of response accuracy as participants progressed through experimental sessions. To ensure each participant saw all 36 experimental articles in a randomized order, we created three stimulus sets with four articles in each condition 
(e.g., four articles with single word highlighting, four articles with full sentence highlighting, and four articles with no highlighting), totaling 12 articles per set. We programmed E-Prime ${ }^{\circledR}$ to present the four articles within each condition in a randomized order across participants. During each of the three sessions, participants completed the experimental task with a different EPrime $^{\circledR}$ stimulus set, allowing for exposure to all stimulus articles across the course of the study. An example screen display of what participants saw during the study appears in the Appendix.

Preference selection materials. We used the practice articles from each condition to create a set of PowerPoint ${ }^{\odot}$ slides so participants could recall each condition to facilitate the expression of their presentation condition preferences.

\section{Procedures}

Institutional Review Boards at both universities at which data collection occurred approved the study materials and procedures prior to participant recruitment and data collection. Given that study participants exhibited chronic aphasia and some had testing available from prior participation in research studies or clinical services, we accessed existing records instead of performing repeat testing with a given assessment tool when possible. If assessment results were more than one year old or were not available, we administered the $W A B-R$ during the first session or during an additional testing session, as needed.

Stimulus articles and comprehension question presentations. A researcher read aloud the written instructions displayed on the laptop screen prior to beginning each experimental session. A practice article matching each subsequent condition appeared on the screen allowing a participant to adjust the volume of the computer-generated speech output, practice using the touchscreen to respond to comprehension questions, and demonstrate understanding of task instructions. After responding to practice article questions, participants touched a green Go icon to advance the presentation software to the first experimental article. The associated auditory recording and text highlighting, as appropriate for a given condition, began one second after appearance of the article text. As soon as the auditory rendition of the article ended, the written text disappeared, and the first comprehension question appeared on the screen.

Participants could not refer back to an article when answering comprehension questions. A researcher read each question and the corresponding response options aloud to participants unless someone expressed a desire to read them independently. Participants selected an answer by touching a circle to the left of one of the possible responses. They could change an answer 
multiple times before progressing to the next question; however, once they indicated either verbally or gesturally a final response selection, the researcher progressed the screen to the next question, and participants could not go back to a previous question. As desired, participants could request breaks between articles or conditions.

Each condition presentation began with a practice article followed by three practice questions. After the practice, participants performed the experimental task with four articles presented with highlighting matching the practice condition. The process repeated for each condition, resulting in exposure to 12 experimental articles and responses to the associated comprehension questions during a single session. Participants completed two additional sessions using the same procedures within two weeks of the initial session. Thus, in total, participants responded to question sets about 36 unique articles, 12 in each of the three experimental conditions.

Participant preference. Participants ranked each of the three highlighting conditions from most to least preferred after completing all three experimental sessions. We prompted participants with questions to determine their condition preference ranking (e.g., Which did you like best? Which did you like least?). If the participants requested to see the conditions again, we showed the PowerPoint ${ }^{\odot}$ slides that displayed each of the practice stories to help them recall the conditions. Participants provided verbal and gestural (e.g., thumbs up) explanations, as possible given speech and language deficits, for their rankings.

\section{Data Analysis}

Variables of interest included: (a) comprehension accuracy for each highlighting condition and (b) participants' preference rankings of the conditions.

Comprehension accuracy. We performed a repeated measures analysis of variance (ANOVA) to identify any significant accuracy difference among the single word, sentence, and no highlighting conditions.

Participant condition preference. We determined condition preference by totaling the number of participants who selected each highlighting condition as their most and least preferred at the end of the third experimental session. We transcribed all participant verbalizations and salient gestures/facial expressions regarding highlighting preferences as well as any explanations participants offered about reading strategies used to facilitate experimental task performance. We 
examined the rationales provided by participants for each condition and coded responses as expressing solely positive, solely negative, mixed reviews, or indifferent feelings.

\section{Results}

\section{Comprehension Accuracy}

Participants achieved the highest average comprehension accuracy score in the single word highlighting condition (range: $38.89-90.28, M=68.07, S D=13.82$ ), followed by the full sentence highlighting condition (range: $38.89-88.89, M=67.02, S D=14.50$ ), and no highlighting condition (range: 40.28 - 93.06, $M=65.5, S D=14.82$ ). Figure 1 represents both individual and full group data. Computation of a repeated measures ANOVA revealed no significant accuracy difference across conditions, $F_{(2,48)}=1.311, p=.274$.

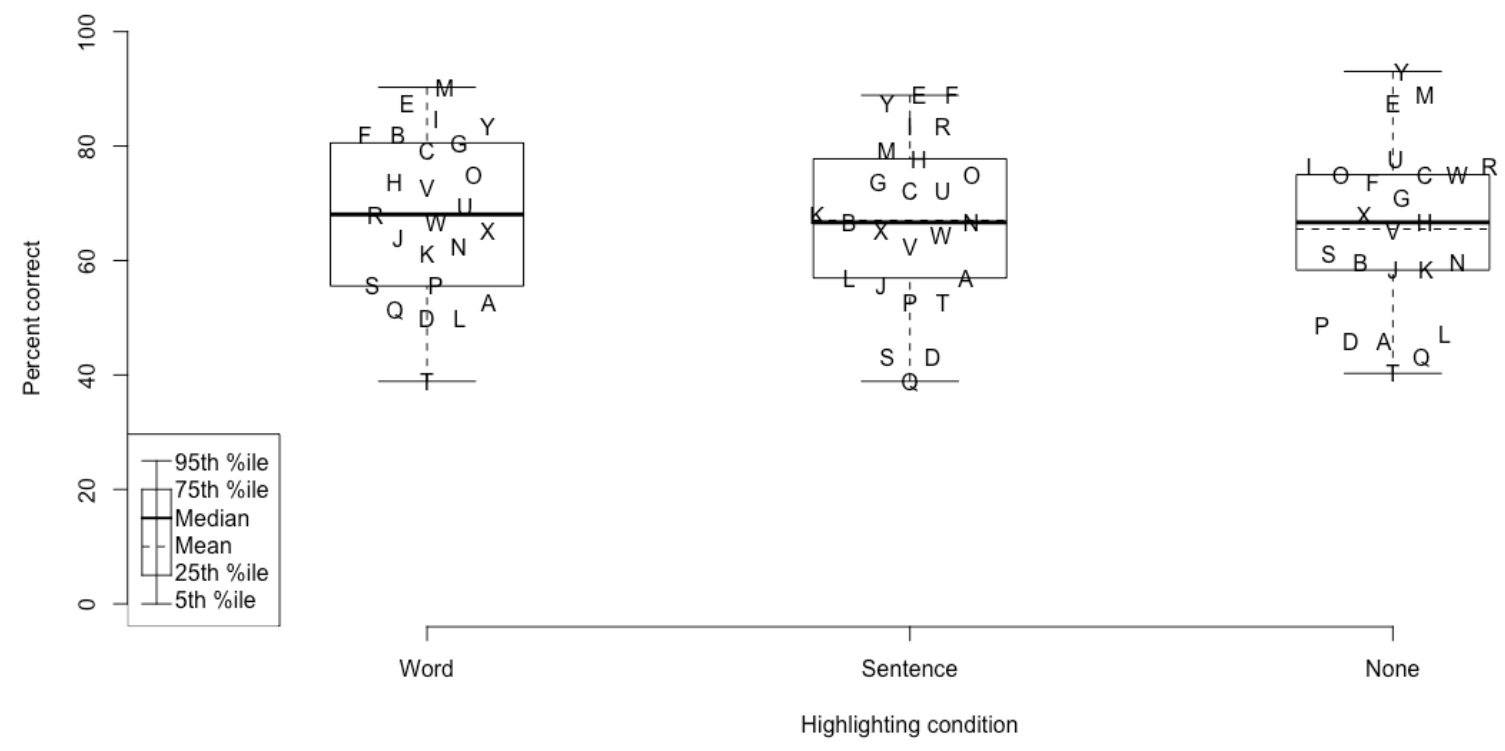

Figure 1. Participants’ percent accuracy across conditions. 


\section{Unique Individual Cases}

For the participants as a whole, there was no significant difference in comprehension accuracy amongst the conditions. However, two participants exhibited a clinically significant differences, greater than 18\%, across two conditions. Specifically, Participant B exhibited a $22.22 \%$ difference in comprehension accuracy between the single word highlighting (81.94\%) and the no highlighting (59.72\%) conditions. In contrast, Participant S demonstrated an 18.06\% difference in comprehension accuracy between the no highlighting (61.11\%) and sentence highlighting conditions (43.06\%) conditions.

\section{Condition Preferences and Perceptions}

Participants ranked highlighting conditions according to preference following completion of the third experimental session. As a group, participants expressed greatest preference for the sentence highlighting condition, followed by word highlighting, and no highlighting. The least preferred condition was the no highlighting condition.

\section{Table 4}

Number of Participants Preferring each Highlighting Condition

\begin{tabular}{cccccc}
\hline \multicolumn{3}{c}{ Most preferred condition } & \multicolumn{3}{c}{ Least preferred condition } \\
\hline \multirow{2}{*}{ Word } & Sentence & None & Word & Sentence & None \\
\hline \multirow{2}{*}{9} & $\mathbf{1 3}$ & 3 & 7 & 3 & $\mathbf{1 5}$ \\
\hline
\end{tabular}

Note. Bold font indicates condition most and least preferred by the greatest number of participants. 


\section{Participant Explanations for Highlighting Preferences}

Participants provided rationales, as possible given expressive language limitations, for their highlighting preference selections. Differing opinions emerged regarding the benefits and detriments associated with each highlighting condition.

Sentence highlighting. Participants most frequently preferred the sentence highlighting condition; however, comments regarding the condition differed across participants. Fourteen participants expressed solely positive comments about sentence highlighting, five expressed solely negative comments, two expressed mixed opinions, and four expressed indifference. Positive comments focused on how sentence highlighting increased the ability to follow the auditory presentation of the story and comprehend the text. In contrast, distractibility and a decreased ability to keep up with the highlighted text were provided as rationales for not liking sentence highlighting. Representative participant comments about the sentence highlighting condition appear in Figure 2. 
Figure 2. Participant Opinions about Sentence Highlighting.

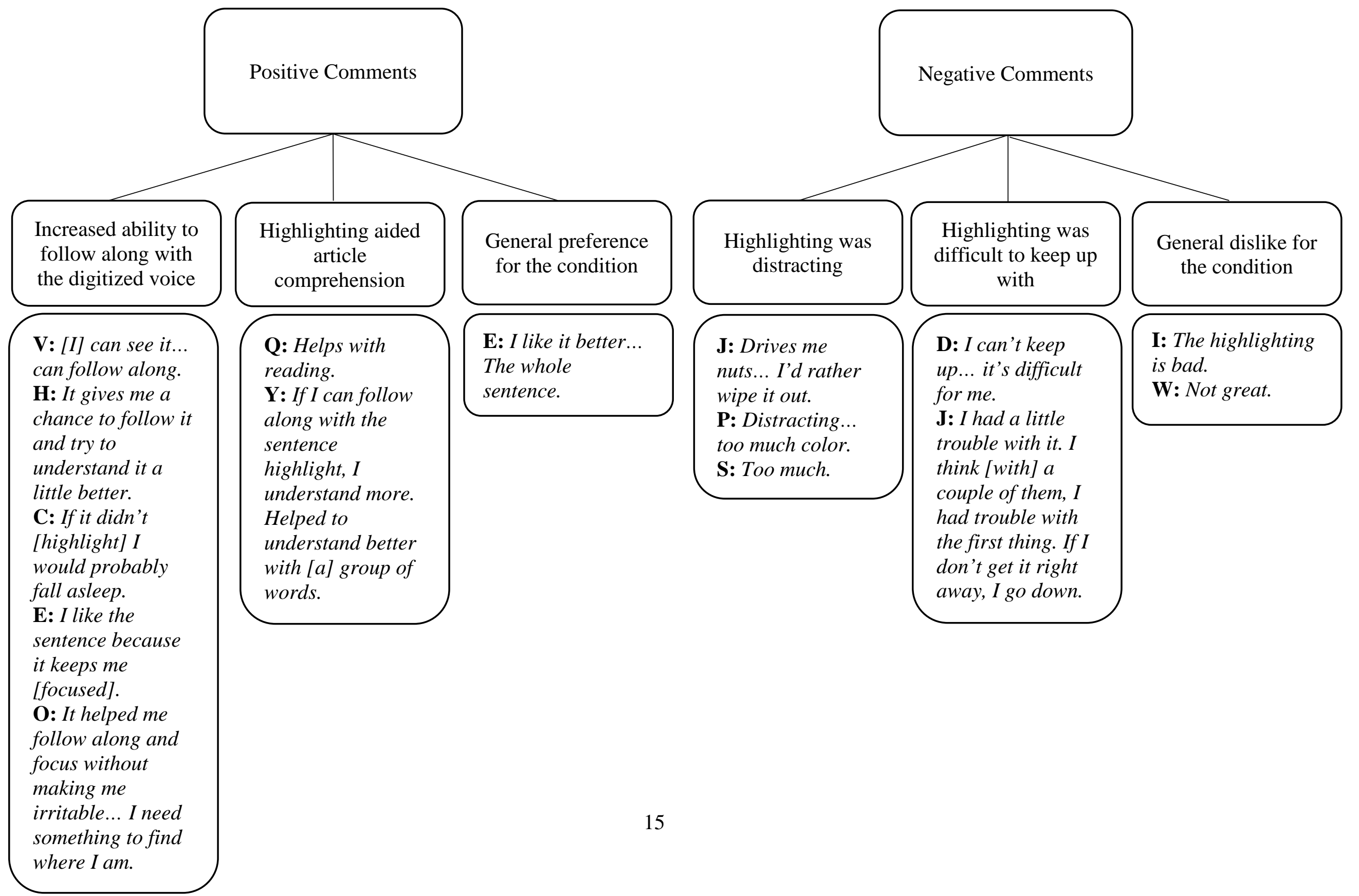


Single word highlighting. Several participants made positive comments regarding the single word highlighting condition even though it was not most preferred by the group as a whole. Participants' opinions differed about benefits and detriments of single word highlighting. Twelve participants expressed exclusively positive comments regarding the condition, seven expressed exclusively negative comments, two expressed mixed opinions, and four expressed feelings of indifference. Positive comments centered on how single word highlighting increased the ability to follow the auditory presentation of the story and comprehend the text. In contrast, distractibility and feelings of agitation from the highlighted text were provided as rationales for not liking sentence highlighting. Representative participant comments about the single word highlighting condition appear in Figure 3. 
Figure 3. Participant Opinions about Single Word Highlighting.

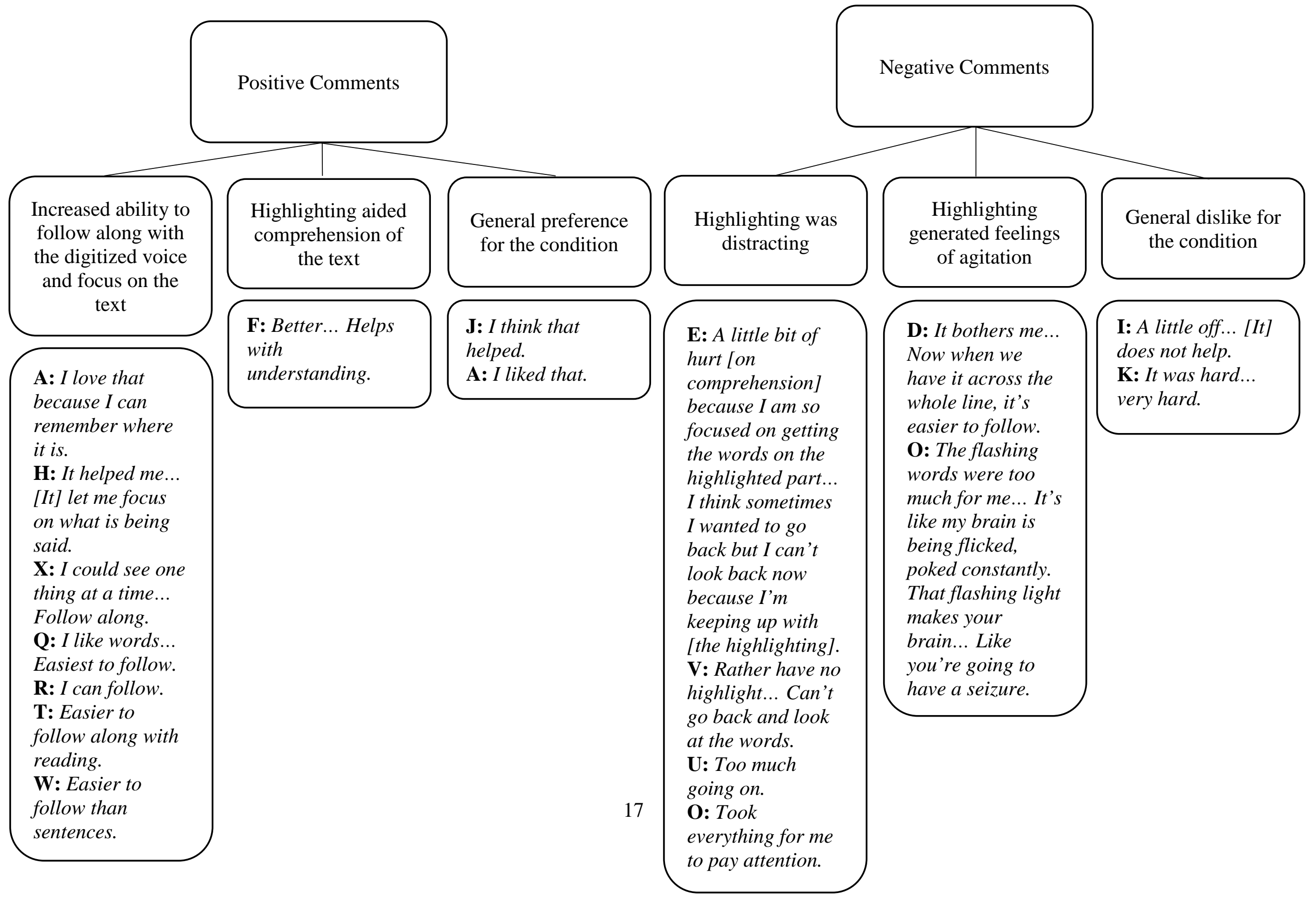


No highlighting. Participants expressed mixed opinions about the no highlighting condition even though the group as a whole least preferred it. Eight participants expressed only positive comments about no highlighting, ten expressed only negative comments, two expressed mixed opinions, and five expressed feelings of indifference. Positive comments focused on how no highlighting was most familiar, similar to reading at home, and aided text comprehension. In contrast, difficulty following along with the digitized voice and feeling a decreased ability to comprehend the text were provided as rationale for not preferring the condition without highlighting. Participant comments regarding the no highlighting condition can be found in Figure 4. 
Figure 4. Participant Opinions about No Highlighting.

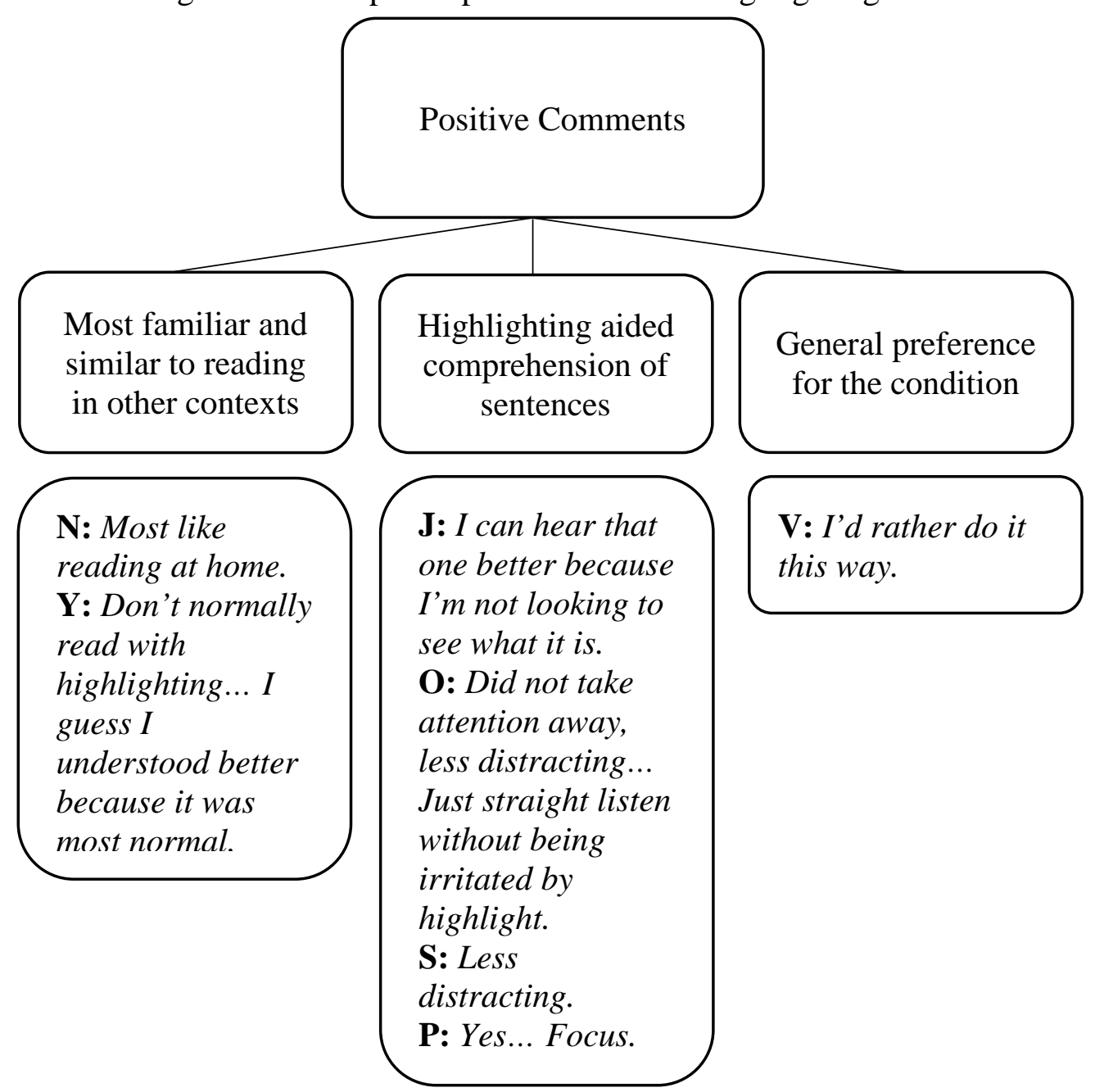

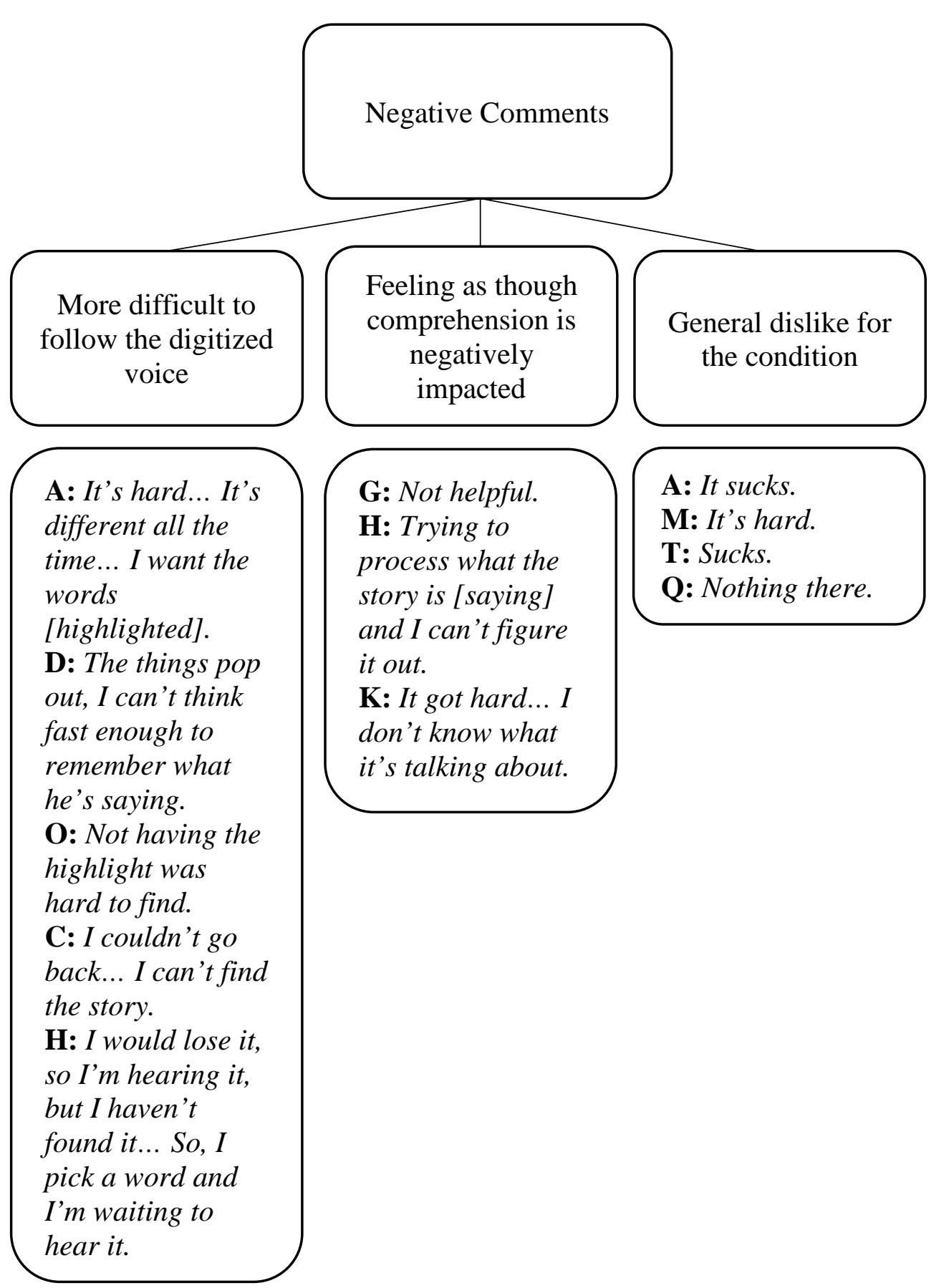




\section{Discussion}

Impaired comprehension abilities after aphasia are often chronic and affect a variety of activities (Holland, 2007; Parr 1995). Still, people with aphasia have a strong desire to regain reading skills and engage with written materials conveying personally relevant content (Knollman-Porter et al., 2015). Consequently, exploring methods of facilitating independent processing of written content by people with aphasia is a clinically relevant goal.

The purpose of this study was to evaluate effects on the comprehension of people with aphasia by adding synchronized digital highlighting to TTS output. We also examined the preferences of people with aphasia about highlighting options. The findings may inform clinicians about potential benefits and detriments associated with implementing highlighting features available via TTS technology and the importance of considering both comprehension accuracy and personal preferences when selecting support strategies.

\section{Comprehension Accuracy}

No significant difference in comprehension accuracy emerged across conditions for participants as a whole, even though individual differences were noted for a few participants. These findings are consistent with the literature regarding highlighting use with children with developmental reading challenges (Ayres et al., 2008; Keelor, 2017; Keelor et al., 2018). Therefore, our hypothesis that highlighting would help reduce the effects of attentional problems of people with aphasia and in turn improve reading comprehension was not borne out by the findings, even though many participants preferred one or both of the highlighting conditions over the no highlighting condition. Because we know people with different aphasia profiles perform differently across comprehension tasks (Helm-Estabrooks et al., 2014; DeDe, 2013), following initial analysis, we examined differences in comprehension accuracy between participants with fluent aphasia versus nonfluent aphasia. We did not find a significant difference in comprehension accuracy between the two groups across the three conditions.

Previous researchers suggest that dual modality presentation (i.e., presenting simultaneous written and auditory) improves comprehension for some people with aphasia during reading tasks (Knollman-Porter et al., 2019; Wallace et al., 2019). However, the addition of a third modality (i.e., digital highlighting in conjunction with simultaneous written and auditory modalities) does not appear to help or hinder comprehension for many individuals. One possible reason for this is the text highlighting occurred at a rate that is too fast or too slow for 
the person with aphasia to comprehend the information. Some participant comments included not being able to keep up with the highlighting or feeling as though they could not go back to re-read important details in order to follow along with the highlighted words. As a result, the individual may have experienced an increased ability to track the highlighting but may not have experienced an increase in comprehension due to the speed of the TTS and highlighting. If each individual were able to control the rate of the TTS and highlighting, a greater comprehension benefit may have been experienced.

Another possibility for the lack of significant results for comprehension accuracy is that the addition of digital highlighting to simultaneous written and auditory presentation may tax limited cognitive resources available to people with aphasia. These findings are in accordance with other researchers' notion that the language challenges of people with aphasia may reflect insufficient capacity and/or inefficient allocation of cognitive resources (Hula \& McNeil, 2008; McNeil et al., 1991; Murray, 1999). If the addition of highlighting does in fact exceed an individual's capacity to process incoming information, the benefits provided by dual modality presentations may be decreased. Additionally, for some, a decrease in comprehension may occur due to the distractibility of the highlighting. Some participant comments centered around the highlighting being too distracting as they were trying to read. If an individual experiences attention deficits, highlighting in conjunction with TTS may distract readers more than it helps.

\section{Individual Differences}

Though no significant comprehension accuracy difference occurred between the participant groups, two participants (i.e., B and S) exhibited notable comprehension differences between two of the conditions. Participant B achieved a comprehension accuracy score in the single word condition that was more than $20 \%$ higher than in the no highlighting condition. For this individual, such a difference in comprehension accuracy between single word and no highlighting may warrant the use of single word highlighting as a reading support strategy. The success of this individual participant suggests that the use of digital highlighting as a reading comprehension support strategy should not be eliminated based on the group results.

Conversely, Participant S experienced nearly a 20\% decrease in comprehension accuracy during the sentence highlighting condition as opposed to the no highlighting condition. In this instance, the use of sentence highlighting was detrimental to the individual's comprehension accuracy and the utilization of sentence highlighting would not be appropriate as a reading support strategy. 
The benefits and consequences experienced by these two participants demonstrate how highlighting can be beneficial to some but detrimental to others. For some individuals, exploring the effects of digital highlighting on reading comprehension may be warranted.

\section{Highlighting Preference}

Participants, as a group, most preferred either single word or sentence highlighting ( $\mathrm{n}=$ 22 ) over the no highlighting condition ( $n=3)$; the majority $(n=15)$ of participants least preferred the no highlighting condition. Respecting the preferences of people with aphasia when recommending support strategies is imperative, especially given the lack of significant comprehension differences across highlighting conditions. Previous researchers have emphasized the importance of considering the opinions of people with aphasia to identify their goals and to help close the gap between what they want, need, and currently can do (Byng \& Duchan, 2005; Duchan \& Black, 2001; Helm-Estabrooks et al., 2014; LPAA Project Group, 2000). Selecting and implementing desired support strategies increases the likelihood of consistent use, which in turn leads to additional practice and greater likelihood of achieving more functional gains (Dalemans et al., 2008; Wepman, 1953; Worrall et al., 2011).

As such, we noted important individual differences to be evident regarding highlighting preferences. Some of our participants made comments about following the printed words to read along while hearing the auditory output of experimental passages. However, others commented about being unsuccessful in doing this given the full sentence and/or single word presentation condition. Some comments related to the highlighting being a distractor, while other comments expressed feeling the inability to go back through the passage to re-read details. This provides us with information about unique and individualized needs when considering which reading supports to utilize.

\section{Clinical Application}

The lack of significant comprehension benefit yet strong preference for either single word or sentence highlighting makes the provision of strategy use recommendations for people with aphasia difficult at best. Clinicians may want to evaluate the patient's comprehension accuracy with and without digital highlighting before implementing it as a reading comprehension support strategy. If assessment results reveal no significant impact on reading comprehension, deferring to participant preference is appropriate. However, because synchronized digital text highlighting 
differs from traditional reading, exposing people to this support on multiple occasions prior to final recommendation and implementation may be wise.

\section{Limitations}

This study included participants with varying aphasia severities. Because the number of participants in each aphasia severity group varied greatly, we chose not to complete statistical analyses regarding impact of these variables on comprehension and preference. Studies with more homogenous participant populations or larger numbers of participants exhibiting varying aphasia characteristics may reveal differences regarding for whom digital text highlighting is or is not beneficial.

We selected newspaper articles so that experimental stimuli could simulate functional, real-world text readily available to people with aphasia. However, to enhance internal validity, we modified the stimuli in various ways (e.g., length, reading grade level, inclusion of quotations, highlighting consistency) to ensure that length and reading grade level were comparable across articles. This resulted in materials that were representative of some, but not all, newspaper articles. To present these articles in each experimental condition, we also used Kurzweil $3000^{\circledR}$; on some occasions we had to alter article formatting in order for the experimental stimuli to highlight consistently across conditions. Presentation of unedited newspaper articles and use of different digital reading software would likely alter study results both in terms of reading comprehension and preference secondary to variability in features provided between systems.

\section{Future Directions}

We administered a broad cognitive assessment to each participant prior to study initiation; however, additional evaluation of specific cognitive abilities (e.g., attention, working memory) was not conducted. Thus, we could not consider fully the contribution of cognitive impairments on participants' reading comprehension abilities when presented with TTS and digital highlighting. A more sensitive cognitive processes assessment may have provided an insight necessary to fully evaluate the effect of digital highlighting on reading comprehension by people with aphasia. Future researchers may wish to consider this when exploring further this type of reading support. Also, assessing the attentional abilities of people with aphasia can be challenging because language and cognitive deficits influence one another (Connor \& Fucetola, 2011; Helm-Estabrooks, 2002; Keil \& Kaszniak, 2002); hence, nonverbal assessments may be 
preferred to verbal ones. The Conners' Continuous Performance Test (CPT-2; Conners, 2002) and the Test of Variables of Attention (TOVA; Leark et al., 1998-1999) are examples of attention assessments that do not require an oral response and may provide a more suitable measure of attentional abilities among people with aphasia (Connor \& Fucetola, 2011).

An important consideration when studying the effects of digital highlighting on reading comprehension is the extent to which people actually track the highlighted words as they are spoke aloud. Using eye-tracking technology may prove useful to monitor the eye movements of a person with aphasia while reading, as researchers have done with other populations (e.g., Ikeshita et al., 2018). Such procedures may provide clinicians with direction about optimal methods of supporting reading by people with aphasia.

\section{Conclusion}

The results of this study did not yield a significant difference on comprehension accuracy across the three conditions. However, some people with aphasia may benefit from the use of digital highlighting in conjunction with TTS to enhance reading comprehension efforts, as supported by individual performance for two cases. Furthermore, the majority of the participants preferred one of the highlighting conditions over no highlighting. Overall, the findings suggest that clinicians should individualize the use of supports when curating a reading comprehension plan for a person with aphasia, taking into consideration both comprehension accuracy and individual preference. 


\section{References}

Ayres, K. M., Langone, J., Douglas, K., Mead, C., \& Bell, V. (2008). Structural analysis of video supported electronic text for learners with moderate intellectual disabilities: A pilot investigation into assistive technology supports. Unpublished manuscript, University of Georgia, Athens.

Baddeley, A. D. (2000). The episodic buffer: A new component of working memory? Trends in Cognitive Sciences, 4, 417-423.

Baddeley, A. D., Wilson, B. A., \& Watts, F. N. (1995). Handbook of Memory Disorders. England: Jon Wiley \& Sons.

Brennan, A., Worrall, L., \& McKenna, K. (2005). The relationship between specific features of aphasia-friendly written material and comprehension of written material for people with aphasia: An exploratory study. Aphasiology, 19, 693-711. doi:10.1080/02687030444000958

Brock, S. E., \& Knapp, P. K. (1996). Reading comprehension abilities of children with attentiondeficit/hyperactivity disorder. Journal of Attention Disorders, 1, 173-185. doi: $\underline{10.1177 / 108705479600100305}$

Byng, S., \& Duchan J. (2005). Social model philosophies and principles: Their application to therapies for aphasia. Aphasiology, 19, 906-922. doi: 10.1080/02687030544000128

Cain, K., Oakhill, J., \& Bryant, P. (2004). Children's reading comprehension ability: Concurrent prediction by working memory, verbal ability, and component skills. Journal of educational psychology, 96, 31-42.

Carretti, B., Borella, E., Cornoldi, C., \& de Beni, R. (2009). Role of working memory in explaining the performance of individuals with specific reading comprehension difficulties: A meta-analysis. Learning and Individual Differences, 19, 246-251. doi: 10.1016/j.lindif.2008.10.002

Catts, H. W., Fey, M. E., Zhang, X., \& Tomblin, J. B. (1999). Language basis of reading and reading disabilities: Evidence form a longitudinal investigation. Scientific Studies of Reading, 3, 331-361. doi: 10.1207/s1532799xssr0304_2

Connor, L. T., \& Fucetola, R. P. (2011). Assessment of attention in people with aphasia: Challenges and recommendations. Perspectives on Neurophysiology and Neurogenic Speech and Language Disorders, 21(2), 55-63. doi: 10.1044/nnsld21.2.55 
Conners, C. K., \& MHS Staff (2002). Conners' CPTII computer program for Windows technical guide and software manual. Multi-Health Systems.

Cutting, L. E., Materek, A., Cole, C. A. S., Levine, T. M., \& Mahone, E. M. (2009). Effects of fluency, oral language and executive function on reading comprehension performance. Annals of Dyslexia, 59, 34-54.

Dalemans, R. J. P., De Witte, L., Wade, D. T., \& Van Den Heuvel, W. J. A. (2008). A description of social participation in working-age persons with aphasia: A review of the literature. Aphasiology, 22, 1071-1091. doi: 10.1080/02687030701632179

DeDe, G. (2013). Reading and listening in people with aphasia: Effects of syntactic complexity. American Journal of Speech Language Pathology, 22, 579-590.

Duchan J., Black M. (2001). Progressing toward life goals: A person-centered approach to evaluating therapy. Topics in Language Disorders, 21(4), 37-49.

Ericsson, K. A., \& Kintsch, W. (1995). Long-term working memory. Psychological Review, 102, 211-245. doi: 10.1037/0033-295X.102.2.211

Friedmann, N., \& Gvion, A. (2003). Sentence comprehension and working memory limitation in aphasia: A dissociation between semantic-syntactic and phonological reactivation. Brain and Language, 86(1), 23-39. doi: 10.1016/S0093-934X(02)00530-8

Gibson E. (2006). The interaction of top-down and bottom-up statistics in the resolution of syntactic category ambiguity. Journal of Memory and Language, 54, 363-388. doi: 10.1016/j.jml.2005.12.005

Helm-Estabrooks, N. (2017). Cognitive-Linguistic Quick Test - Plus. The Psychological Corporation.

Helm-Estabrooks, N. (2002). Cognition and aphasia: A discussion and a study. Journal of Communication Disorders, 35, 171-186. doi: 10.1016/S0021-9924(02)00063-1

Helm-Estabrooks, N., Albert, M. L., \& Nicholas, M. (2014). Manual of aphasia and aphasia therapy (3rd ed.). Pro-Ed.

Holland, A. L. (2007). Counseling/coaching in chronic aphasia: Getting on with life. Topics in Language Disorders, 27(4), 339-350. doi: 10.1097/01.TLD.0000299888.24241.dd.p

Hook, P. E., \& Crawford-Brooke, C. (2015). Teaching the fundamentals of reading: Word identification and fluency. In T. A. Ukrainetz (Ed.), School-age language intervention: Evidence-based practices (pp. 491-525). PRO-ED. 
Hula, W. D., \& McNeil, M. R. (2008). Models of attention and dual-task performance as explanatory constructs in aphasia. Seminars in Speech and Language, 29, 169-187. doi: 10.1055/s-0028-1082882

Huppert, F. A., \& Piercy, M. (1982). In search of the functional locus of amnesic syndromes. In Cermak, L. S. (Ed.). Human memory and amnesia (123-137). Psychology Press.

Hux, K., Brown, J., Wallace, S. E., Knollman-Porter, K., Saylor, A., \& Lapp, E. (In press). Effect of text-to-speech rate on reading comprehension by adults with aphasia. American Journal of Speech-Language Pathology.

Ikeshita, H., Yamaguchi, S., Morioka, T., \& Yamazoe, T. (2018). Effects of Highlighting Text on the Reading Ability of Children with Developmental Dyslexia: A Pilot Study. International Journal of Emerging Technologies in Learning (iJET), 13, 239-251. doi: 10.3991/ijet.v13i09.8736

Jiang, H., \& Farquharson, K. (2018). Are working memory and behavioral attention equally important for both reading and listening comprehension? A developmental comparison. Reading and writing, 31, 1449-1477. doi: 10.1007/s11145-018-9840-y

Johnson, R. L. \& Rayner, K. (2007). Top-down and bottom-up effects in pure alexia: Evidence from eye movements. Neuropsychologia, 45, 2246-2257. doi: 10.1016/j.neuropsychologia.2007.02.026

Keelor, J. (2017). Examining Comprehension of Children with Reading Difficulty following Reading with Text-to-Speech Features. (Electronic Thesis or Dissertation). Ohio LINK. https://etd.ohiolink.edu/

Keelor, J., Creaghead, N., Silbert, N., Breit-Smith, A., Horowitz-Kraus, T. (2018). Language, reading, and executive function measures as predictors of comprehension using text-tospeech. Reading, \& Writing Quarterly, 34, 436-450. doi: 10.1080/10573569.2018.1486764

Keil, K., \& Kaszniak, A. W. (2002). Examining executive function in individuals with brain injury: A review. Aphasiology, 16, 305-335. doi: 10.1080/02687030143000654

Kendeou, P., van den Broek, P., Helder, A., \& Karlsson, J. (2014). A cognitive view of reading comprehension: Implications for reading difficulties. Learning Disabilities Research and Practice, 29, 10-16. doi: 10.1111/ldrp.12025

Kertesz, A. (2006). Western Aphasia Battery - Revised. Pearson Education. 
Knollman-Porter, K., Wallace, S. E., Brown, J. A., Hux, K., Hoagland, B. L., \& Ruff, D. R. (2019). Effects of written, auditory, and combined modalities on comprehension by people with aphasia. American Journal of Speech-language Pathology, 28, 1206-1221. doi: 10.1044/2019_AJSLP-19-0013

Knollman-Porter, K., Wallace, S. E., Hux, K., Brown, J., \& Long, C. (2015). Reading experiences and use of supports by people with aphasia. Aphasiology, 29, 1448-1472. doi: 10.1080/02687038.2015.1041093

LaPointe, L., \& Horner, J. (1998). RCBA-2: Reading Comprehension Battery for Aphasia Second Edition. PRO-ED.

Leark, R. A., Dupuy, T. R., Greenberg, L. M., Corman, C. L., \& Kindschi, C. L. (1998-1999). Test of variables of attention: Professional guide. Universal Attention Disorders.

Leff, A., \& Behrmann, M. (2008). Treatment of reading impairment after stroke. Current Opinion in Neurology, 21(6), 644-648. doi:10.1097/WCO.0b013e3283168dc7

LPAA Project Group (Chapey, R., Duchan, J. F, Elman, R. J., Garcia, L. J., Kagan, A., Lyon, J., \& Simmons Mackie, N. (2000). Life participation approach to aphasia: A statement of values for the future. ASHA Leader, 5(3), 4-6. doi: 10.1044/leader.FTR.05032000.4

Martin, R. C., \& Allen, C. M. (2008, August). A disorder of executive function and its role in language processing. Seminars in Speech and Language, 29, 201-210. doi: 10.1055/s-00281082884

Martinussen, R., \& Mackenzie, G. (2015). Reading comprehension in adolescents with ADHD: Exploring the poor comprehender profile and individual differences in vocabulary and executive functions. Research in Developmental Disabilities, 38, 329-337. doi: 10.1016/j.ridd.2014.12.007

McNeil, M. R., Odell, K., \& Tseng, C. H. (1991). Toward the integration of resource allocation into a general theory of aphasia. Clinical Aphasiology, 20, 21-39.

Murray, L. L. (2002). Attention deficits in aphasia: Presence, nature, assessment, and treatment. In Seminars in speech and language, 23, 107-116. doi: 10.1055/s-2002-24987

Murray, L. L. (1999). Review attention and aphasia: Theory, research and clinical implications. Aphasiology, 13, 91-111. doi: 10.1080/026870399402226 
Oakhill, J., \& Cain, K. (2012). The precursors of reading comprehension and word reading in young readers: Evidence from a four-year longitudinal study. Scientific Studies of Reading, 16, 91-121. doi: 10.1080/10888438.2010.529219

Oakhill, J., \& Yuill, N. (2013). Higher order factors in comprehension disability: Processes and remediation. In Reading comprehension difficulties: Processes and intervention. (93-116). Routledge.

Parr, S. (1995). Everyday reading and writing in aphasia: Role change and the influence of premorbid literacy practice. Aphasiology, 9, 223-238. doi: 10.1080/02687039508248197

Perfetti, C. A., Stafura, J. Z., \& Adlof, S. M. (2013). Reading comprehension and reading comprehension problems: A word-to-text integration perspective. In B. Miller, L. Cutting, \& P. McCardle (Eds.). Unravelling the Behavioral, Neurobiological, and Genetic Components of Reading Comprehension. (22-32). Paul Brookes Publishing.

Posner, M. I., \& Petersen, S. E. (1990). The attention system of the human brain. Annual Review of Neuroscience, 13(1), 25-42.

Rashotte, C. A., MacPhee, K., \& Torgesen, J. K. (2001). The effectiveness of a group reading instruction program with poor readers in multiple grades. Learning Disability Quarterly, 24, 119-134. doi: 10.2307/1511068

Rayner, K., \& Johnson, R. L. (2005). Letter-by-letter acquired dyslexia is due to the serial encoding of letters. Psychological Science, 16, 530-534. doi: 10.1111/j.09567976.2005.01570.x

Samuels, S. J., \& Flor, R. F. (1997). The importance of automaticity for developing expertise in reading. Reading \& Writing Quarterly, 13, 107-122. doi: 10.1080/1057356970130202.

Seigneuric, A., \& Ehrlich, M. F. (2005). Contribution of working memory capacity to children’s reading comprehension: A longitudinal investigation. Reading and Writing: An Interdisciplinary Journal, 18, 617-656. doi: 10.1007/s11145-005-2038-0

Seigneuric, A., Ehrlich, M.-F., Oakhill, J. V., \& Yuill, N. M. (2000). Working memory resources and children's reading comprehension. Reading and Writing: An Interdisciplinary Journal, 13, 81-103. doi: 10.1023/A:1008088230941

Sesma, H. W., Mahone, E. M., Levine, T., Eason, S. H., \& Cutting, L. E. (2009). The contribution of executive function to reading comprehension. Child Neuropsychology, 15, 232-246. doi: 10.13016/M2GQ6R56R 
Swanson, H. L. (1999). Reading comprehension and working memory in learning-disabled readers: Is this phonological loop more important than the executive system? Journal of Experimental Psychology, 72, 329-331. doi: 10.1006/jecp.1998.2477

Swinburn, K., Porter, G., \& Howard, D. (2004). Comprehensive Aphasia Test. Psychology Press.

Wallace, S. E., Knollman-Porter, K., Brown, J. A., \& Hux, K. (2019). Narrative comprehension by people with aphasia given single versus combined modality presentation. Aphasiology, 33, 731-754. doi: 10.1080/02687038.2018.1506088

Wepman, J. M. (1953). A conceptual model for the process involved in recovery from aphasia. Journal of Speech and Hearing Disorders, 18, 4-13. doi: 10.1044/jshd.1801.04.

Worrall, L., Sherratt, S., Rogers, P., Howe, T., Hersh, D., Ferguson, A., \& Davidson, B. (2011). What people with aphasia want: Their goals according to the ICF. Aphasiology, 25, 309-322. doi: 10.1080/02687038.2010.508530

Wright, H. H., Shisler, R. J. (2005). Working memory in aphasia: Theory, Measures, and Clinical Implications. American Journal of Speech-Language Pathology, 14, 107-118. 


\section{Appendix}

Example Article with the Sentence Highlighting Condition

\section{Award Winning Tree in Ludington}

The Official Tree Board of Ludington, Michigan presented a certificate to Noah and Amelia Robinson for two noble fir trees on the front lawn of their residence on N Haas Street. The trees are the first within the city limits to enter the Prestigious Tree Program administered by the tree board.

The noble fir trees were estimated to be planted in September of 1907 by William and Helen Davis. The 112-year-old trees stand nearly 80 feet tall and each have a diameter of about three and a half feet round. The front lawn where the trees are planted is known as the most photographed spot in Ludington.

The Prestigious Tree Program is open to all species of trees. To enter the program, trees must be healthy trees located within the United States and must meet one or more of the tree board's criteria. Ludington's noble fir trees were admitted to the program for being greater than 50 years old as determined by the opinion of an Arborist and for being considered Landmark Trees. Residents are encouraged to submit their trees to the Ludington Tree Board as a part of the "Keep Ludington Beautiful” Project. The project is dedicated to engaging all citizens in every aspect of keeping Ludington clean and beautiful. 